\title{
Utility of Parental Mediation Model on Youth's Problematic Online Gaming
}

\author{
Rahim Benrazavi ${ }^{1} \cdot$ Misha Teimouri $^{2}$ • \\ Mark D. Griffiths ${ }^{3}$
}

(C) Springer Science+Business Media New York 2015

\begin{abstract}
The Parental Mediation Model (PMM) was initially designed to regulate children's attitudes towards the traditional media. In the present era, because of prevalent online media there is a need for similar regulative measures. Spending long hours on social media and playing online games increase the risks of exposure to the negative outcomes of online gaming. This paper initially applied the PMM developed by European Kids Online to (i) test the reliability and validity of this model and (ii) identify the effectiveness of this model in controlling problematic online gaming (POG). The data were collected from 592 participants comprising 296 parents and 296 students of four foreign universities, aged 16 to 22 years in Kuala Lumpur (Malaysia). The study found that the modified model of the five-factor PMM (Technical mediation, Monitoring mediation, Restrictive mediation, Active Mediation of Internet Safety, and Active mediation of Internet Use) functions as a predictor for mitigating POG. The findings suggest the existence of a positive relation between 'monitoring' and 'restrictive' mediation strategies and exposure to POG while Active Mediation of Internet Safety and Active mediation of Internet use were insignificant predictors. Results showed a higher utility of 'technical' strategies by the parents led to less POG. The findings of this study do not support the literature suggesting active mediation is more effective for reducing youth's risky behaviour. Instead, parents need
\end{abstract}

Rahim Benrazavi

rahim.benrazavi@gmail.com

Misha Teimouri

misha.teimmoury@gmail.com

Mark D. Griffiths

mark.griffiths@ntu.ac.uk

1 Faculty of Educational Studies, Department of Professional Development and Continuing Education, Universiti Putra Malaysia, 43400 Serdang, Selangor, Malaysia

2 Faculty of Modern Languages and Communication, Department of Communication, Universiti Putra Malaysia, 43400 Serdang, Selangor, Malaysia

3 International Gaming Research Unit, Psychology Division, Nottingham Trent University, Burton Street, Nottingham NG1 4BU, UK 
to apply more technical mediations with their children and adolescents' Internet use to minimize the negative effects of online gaming.

Keywords Parental mediation model · Problematic youth online gaming · Technical ·

Monitoring $\cdot$ Restrictive $\cdot$ Active mediation of internet safety $\cdot$ Active mediation of internet use

Parents have utilized different measures that are identified in the Parental Mediation Model (PMM) to regulate and control their children's internet use (Nikken and Jansz 2006). The PMM has been also applied to maximize the benefits and minimize the difficulties of adolescents' internet use. Earlier studies have suggested and empirically validated three types of parental mediation (i.e., restrictive mediation, active mediation, and co-use of media) and all these three types of parental mediation have been shown to be applicable for disorders in application of both television and video games (Nikken and Jansz 2006). Restrictive mediation is defined as a set of rules that intend to limit the amount of time that adolescents spend on online media in the case of the present study. Active mediation refers to discussing the negative effects of the media content with adolescents. Co-using mediation refers to parents sharing media experience with their children without any purposeful instructions or critical discussions (Nikken and Jansz 2006). Consequently, scholars should start applying the PMM to test the most effective mediation strategies that increase benefits and decrease threats of internet exposure on youth. It is important to mention that the focus of this study is merely on adolescents. Adolescents in this study have been referred to as children from time to time and that is only once they are looked upon from the point of view of their parents.

The proportion of Malaysian youths in urban areas using the Internet is $90 \%$ (Soh et al. 2012). Higher Internet usage led to higher level of exposure to risky and negative activities such as violent behaviors and gambling (Soh et al. 2012). As the users reach young adulthood (20-24 years old), internet usage increases with $41 \%$ using the internet up to $22.3 \mathrm{~h}$ per week (Ismail 2011). Meanwhile it has been reported that only $40 \%$ of Malaysian parents know about their children's online activities (Ismail 2011).

One negative issue that Malaysian adolescents are associated with is online game addiction and is due to high rates of internet use. Apart from addiction, some online games contain violent and sexual content that bring in further complications. This issue necessitates further understanding on the factors that contribute to adolescents' growing positive attitude towards online games. Studies show that the time spent playing online games has significantly increased in Malaysia over the last decade (Kapahi et al. 2013; Liau et al. 2008). Given that adolescents are increasingly spending longer hours of their time on playing online games, parents have started to be more concerned about this issue. Nevertheless, by applying PMM strategies, researchers hope to come up with a practical solution to minimize the disadvantages of online gaming and internet use.

The present study aimed to identify which parental mediation strategy is more effective in reducing risks caused by online gaming on younger Internet users. This demands checking on the validity and reliability of the PMM in the Malaysian context, since it was validated in European studies but never in the context of Malaysia. The study also aimed to identify the effects of the PMM on problematic online gaming (POG) among youth. 


\section{Parental Mediation Model}

From media studies, much research proposes the necessity of parental assistance in guiding their children's media use (Lee 2012; Nikken and Jansz 2011). Furthermore, there has been increased concern about the negative effects of media on a minority of users including social networking (Griffiths et al. 2014) and online video gaming (Pápay et al. 2014). The effectiveness of the PMM on limiting the application of online media was noted as one of the limitations of Parental Mediation theory (Clark 2011). In prior studies, television was the preferred topic of discussion and investigation. Newer studies still consider traditional parental mediation styles to be applicable for Internet use, but it is difficult to monitor online activities with traditional strategies, therefore new strategies need to be investigated.

As noted, parental mediation role in adolescents' Internet usage has been widely studied by scholars (Daud et al. 2014; Nikken and Jansz 2011; Shin et al. 2012). However, researchers employ different scales and dimensions to measure the parental mediation role within adolescents' media use. The old style of television mediation that parents applied, was called restrictive mediation (Bybee et al. 1982; Atkin et al. 1991; Nathanson 1999). Here, parents simply set rules for viewing certain content. For instance, parents can set the specific number of hours for their child's television viewing, or forbid them to watch a particular television program (Valkenburg et al. 1999). Shek (2005) suggested that parental control strategies should include parental monitoring, knowledge, discipline, and psychological control. Parental monitoring is primarily defined as parental knowledge rather than active parenting strategies for obtaining that knowledge (Stattin and Kerr 2000). Dishion and McMahon (1998) also defined parental monitoring as a set of correlated parenting behaviors that involve paying attention and monitoring adolescents' media adaptations.

As noted earlier, the PMM has been rooted in social/psychological media effects. Within this perspective, two types of parental control have been identified: 'psychological control' and 'behavioral control'. Psychological control refers to "parents' attempt to control the adolescents' activities in ways that negatively affect the adolescents' psychological world and thereby undermines the adolescents' psychological development" (Smetana and Daddis 2002, p. 563) (e.g. invalidating feelings, personal attack, guilt induction, and erratic emotional behavior). Behavioral control refers to "rules, regulations, and restrictions that parents have for their children" (Smetana and Daddis 2002, p. 563). However, as stressed by Shek (2005), there is little research measuring these two psychological controls for media usage.

Following all the attempts made to classify various styles of parental mediation within adolescents' Internet use, active mediation and restrictive mediation are considered as two broad dimensions of parental mediation discussed by some scholars (e.g., Kirkpatrick and Shaver 1990; Shin et al. 2012). Active mediation occurs once parents' explain and discuss media effects with their children. On the other hand, restrictive mediation is an attempt to control adolescents' media use by setting rules based on appropriateness of media content (e.g., content restriction) and media exposure time (e.g., time restriction). These two dimensions (in addition to co-viewing, which refers to the sharing of online experience with adolescents without any critical discussion), have been noted in a number of studies (e.g. Nathanson 1999, 2002, 2010; Shin and Hun 2011; Valkenburg et al. 1999). It is believed that active mediation involves verbal communication between parents and children, while co- 
viewing involves nonverbal communication, and restrictive mediation requires parent-to-child communication in the form of rules.

Research findings suggest that active mediation is more effective in reducing undesirable media effects on adolescents, compared to other parental mediation strategies (Buijzen et al. 2008; Buijzen and Valkenburg 2005). Likewise, Fujioka and Weintraub (2003) believed that active mediation is the most effective strategy since it is built upon conversation and critical discussion between parents and their children, which leads adolescent to develop critical thinking skills. Active mediation has been found to be associated with various positive socialization outcomes in new media and also use of the Internet for educational purposes (Lee and Chae 2007). There are contradictory ideas about restrictive mediation since scholars such as Buijzen and Valkenburg (2005), consider restrictive mediation to be less effective compared to active mediation, while scholars have found it to be more effective in reducing negative influences of the Internet on adolescents, such as exposure to inappropriate content (Livingstone and Helsper 2008), cyberbullying (Mesch 2009), privacy invasion (Lwin et al. 2008), and tweens' information disclosure on the internet (Shin et al. 2012).

Although Lwin et al. (2008) have found that restrictive mediation is less effective compared to active mediation, it was applied significantly more often compared to active mediation, and it is still more effective than non-mediation in reducing negative influences of Internet use in adolescents. Researchers have found that parents are less likely to apply the restrictive mediation policies in the long run as they are generally believed to affect only the immediate behaviours of adolescents, provided that they abide their parents' rules (Shin et al. 2012). If parents strictly limit the amount of time that adolescents can stay online then the adolescent may be less likely to encounter online risks such as marketers requesting personal information. However, such parental restriction strategies that limit adolescents' internet use in general will also reduce their online opportunities for participating in educational, social and entertainment activities as well as productive online communication.

In order to motivate parents to take a more active part in mediating their children's online activities, Livingstone and Helsper (2008) believe that parents might be more involved in guiding their children's Internet use if they found an association between mediation and various positive socialization consequences, in both traditional and new media. More recently, Duerager and Livingstone (2012), developed a new measure from an analysis of an online survey examining internet use in 25,142 children aged between 9 and 16 year old in 25 European countries.

\section{Parental Mediation and Online Game Addiction}

Empirical research has demonstrated that parenting activities have been successful in regulating adolescents' online behavior and mitigating the negative effects of using media. Products of the online media such as online games are among the fastest growing and most profitable entertainments in the online media (Pápay et al. 2014). However, teens and older youth are currently considered as the prime audience of the Internet and related industries such as online gaming. In a study by Azim et al. (2011), it was reported that nearly $39 \%$ of the respondents used the Internet for non-interactive activities, such as playing video games. In an American study by Shin and Huh (2011), the effectiveness of the PMM on controlling teenagers' video game playing and other types of gaming behaviours, was investigated. The three forms of parental mediation policies that were examined in that study were co-playing, game rating 
checking, and stopping adolescents from playing games. The results showed a weak and negative correlation between teenagers' age and parental mediation. In addition, the findings showed that parents who presumed video games had a negative influence were more likely to restrict video game playing. The PMM - particularly on game rating - was significantly related to teenagers' game playing and gaming behaviours (Shin and Huh 2011).

Playing online games is not a risky behaviour on its own and perhaps the parents less particular about this issue share the same viewpoint. However, when adolescents keep doing it in an addictive manner it can become a risky behaviour (Griffiths et al. 2014). Chen (2010), found many factors that contributed to the negative consequences of using online game including time risk, psychological risk, financial risk, physical intangibility, and mental intangibility. However, there is much research showing the educational and therapeutic benefits of video game playing (Griffiths et al. 2013). For instance, in Malaysia, a study by Latif and Sheard (2009), found in a study of 341 public school students that video game playing has benefits such as improving students' communication skills and social skills. Studies have also shown that video games (including online gaming) are very popular among Malaysian adolescents, especially in younger ages. A study by Zin et al. (2009) indicated that $92 \%$ of Malaysian students have played digital games. Of these, $27.7 \%$ had played games for less than $1 \mathrm{~h}$ per week and $16.4 \%$ played for $1 \mathrm{~h}$ and more per week. Furthermore, $83.6 \%$ of the students stated that they liked to play digital or electronic games for fun, while $62.7 \%$ played games just to fill up their free time.

\section{Method}

\section{Participants}

The participants were 592 individuals comprising 296 youth aged 16-22 and one of their parents/guardians, in the state of Selangor, Malaysia. To access this age group four colleges in Kuala Lumpur (Malaysia) were approached. These colleges were the ones with the highest internet usage according to Malaysian Communications and Multimedia Commission (MCMC). Convergent and discriminant validity as well as construct reliability were assessed using structural equation modelling. The samples are selected among the students of four locally based foreign universities that are offering their programs in HELP College of Arts and Technology, namely Southern New Hampshire University, University of London, Anglia Ruskin University and University of Hertfordshire. The sample comprised $51.4 \%$ males and $46.3 \%$ females with the mean age of 12.6 years ( $\mathrm{SD}=2.28$ years). The participants were Chinese (53.7\%), Indian (27.8), Malay (8.4\%) and other (10.1\%).

\section{Materials}

Parental mediation: The instrument to assess parental mediation in this study was adapted to the issue of problematic gaming. The need for this adaptation was because the original instrument was initially designed for internet safety. The parental mediation model (PMM) was assessed using the instrument developed by the EU Kids Online survey (Livingstone et al. 2011). The instrument consisted of five-subscales measuring the respective dimensions of 
Parental Mediation Model constructs. The instrument has 22 items on five-point Likert scales ranging from never (1) to very often (5). More specifically:

- Technical Mediation was assessed with a three-item scale. Parents were asked whether they used any of software to prevent spam or junk mail or viruses, a service or contract that limits the time their children spends on the Internet playing, and keeping track of the inappropriate games they play.

- Monitoring Mediation was assessed with a four-item scale. Parents were asked whether they sometimes checked their children's profile on a gaming community, and what kind of game they are playing.

- Parental Restrictive Mediation was assessed with a four-item scale. Parents were asked whether they practiced restrictive mediation on their children's online activities such as giving out personal information to others in order to play an online game or playing particular game.

- Active Mediation of Internet Safety was assessed with a six-item scale. Parents were asked about their active mediation by asking whether they talked to/help their child about what to do if something bothered him/her while they are playing game; suggested ways to play safely; explained why some game are good or bad.

- Active Mediation of Internet Use was assessed with a five-item scale. Parents were asked if they ever play an online game together with their children; encouraged them to explore and learn things on the Internet on their own; stayed nearby when he/she is playing a video game.

The percentage, mean, and standard deviation of parent/guardian's response to questions measuring PMM are presented in Table 1 (items and construct organised based on highest to lowest mean).

Problematic gaming: The Problematic Online Gaming Questionnaire (POGQ) was used to assess problematic gaming (Demetrovics et al. 2012). They developed 32 items of the POGQ through a comprehensive review of literature and interviews with online gamers, which 15 questions out of 32 questions found to be reliable (Cronbach alpha: 0.9). For this study, the 15item scale was used to measure the level of youth Problematic Online Gaming. Results have been categorised in three level scale (1) never, (2) sometimes, (3) often. The questions, percentage, mean and standard deviation are presented in Table 1. As it shows in Table 1, the highest problematic online game is for item "how often do you play longer than originally planned" (mean: 2.1) (see Tables 2 and 3).

\section{Results}

\section{Exploratory Factor Analyse for Parental Mediation Measurement}

In order to decide how many factors explained 45 items of the Child Online Risk measurement, exploratory factor analyses (EFA) using SPSS 22 with maximum likelihood extraction and Promax rotation was performed. Significant Bartlett's Test of Sphericity (Bartlett 1954) and Kaiser-Meyer-Olkin value $(0.8=>0.6$; Kaiser 1974) demonstrated that the EFA was statistically appropriate. Using Cattell's (1966) scree test, it was decided to retain five components. The five-factor solution explained a total of $40 \%$ of the variance with 
Table 1 The percentages, means and standard deviations of responses to problematic online gaming questions

\begin{tabular}{|c|c|c|c|c|c|}
\hline Items & $1 \%$ & $2 \%$ & $3 \%$ & M & S.D. \\
\hline 1. How often do you play longer than originally planned? & 25.3 & 48.3 & 26.4 & 2.01 & 0.72 \\
\hline $\begin{array}{l}\text { 2. How often do you think about playing a game when you } \\
\text { are not playing? }\end{array}$ & 30.4 & 54.4 & 15.2 & 1.85 & 0.66 \\
\hline $\begin{array}{l}\text { 3. How often do you feel that you should reduce the amount } \\
\text { of time you spend gaming? }\end{array}$ & 34.8 & 50.3 & 14.9 & 1.80 & 0.68 \\
\hline 4. How often do you lose track of time when gaming? & 36.5 & 47.6 & 15.9 & 1.79 & 0.69 \\
\hline 5. How often do you feel time stops while gaming? & 42.6 & 39.5 & 17.9 & 1.75 & 0.74 \\
\hline $\begin{array}{l}\text { 6. How often do you unsuccessfully try to reduce the } \\
\text { time you spend on gaming? }\end{array}$ & 39.9 & 47.3 & 12.8 & 1.73 & 0.67 \\
\hline $\begin{array}{l}\text { 7. How often do you feel depressed or irritable when } \\
\text { not gaming? }\end{array}$ & 41.2 & 47.6 & 11.1 & 1.70 & 0.66 \\
\hline $\begin{array}{l}\text { 8. How often do the people around you complain that } \\
\text { you are gaming too much? }\end{array}$ & 45.3 & 40.2 & 14.5 & 1.69 & 0.71 \\
\hline $\begin{array}{l}\text { 9. How often do you feel that gaming causes problems } \\
\text { for you in your life? }\end{array}$ & 43.2 & 44.6 & 12.2 & 1.69 & 0.68 \\
\hline $\begin{array}{l}\text { 10. How often are you so immersed in gaming that you } \\
\text { forget to eat? }\end{array}$ & 44.3 & 43.9 & 11.8 & 1.68 & 0.68 \\
\hline $\begin{array}{l}\text { 11. How often do you neglect other activities because you } \\
\text { would rather gaming? }\end{array}$ & 43.2 & 46.3 & 10.5 & 1.67 & 0.66 \\
\hline $\begin{array}{l}\text { 12. How often do you get irritable, restless or anxious } \\
\text { when you cannot play games as much as you want? }\end{array}$ & 48.0 & 40.2 & 11.8 & 1.64 & 0.68 \\
\hline $\begin{array}{l}\text { 13. How often do you argue with your parents because of } \\
\text { gaming? }\end{array}$ & 48.3 & 41.2 & 10.5 & 1.62 & 0.67 \\
\hline 14. How often do you daydream about gaming? & 49.3 & 40.2 & 10.5 & 1.61 & 0.67 \\
\hline $\begin{array}{l}\text { 15. How often do you fail to meet up with a friend because } \\
\text { you were gaming? }\end{array}$ & 50.7 & 41.6 & 7.8 & 1.57 & 0.63 \\
\hline
\end{tabular}

1: never, 2: sometimes, 3: often

$M$ Mean, $S D$ Standard deviation

eigenvalues exceeding 1 , explaining $19,6.8,5.5,4.2$, and $4 \%$ of the variance respectively. The result of the EFA is presented in Table 4.

\section{Assessing Measurement Model Validity}

The convergent and discriminant validity, factor loading, construct reliability, construct inter-correlation, and average variance extracted (AVE) were assessed and results are shown in Table 4. Construct reliability and validity of parental mediation was calculated using the Stat Tool Package (Gaskin 2012). To obtain convergent validity, the variables within a single factor must be highly correlated. Sufficient factor loadings depend on the sample size of the data. Hair et al. (2010) suggested that a factor loading more than 0.3 is acceptable for a sample size of more than 350 participants. Hence, items less than 0.3 were deleted. Strong discriminant validity is obtained when variables relate more strongly to their own factor than to another factor, and AVE is also required to be more than 0.05 (Fornell and Larcker 1981) which in this study met the criteria. The results show that there was a weak correlation between factors, meaning that these factors are measuring different things. The internal consistencies of the items within a single factor 
Table 2 The percentages, means and standard deviations of parental responses to parental mediation questions

\begin{tabular}{|c|c|c|c|c|c|}
\hline & Items & Low & High & M & S.D. \\
\hline \multicolumn{6}{|c|}{ Active mediation of Internet safety } \\
\hline 1 & Suggested ways to mind your words/actions while gaming & 50.3 & 49.7 & 1.50 & 0.50 \\
\hline 2 & Suggested ways to do online game safely & 51.0 & 49.0 & 1.49 & 0.50 \\
\hline 3 & Explained why some game are good or bad & 51.7 & 48.3 & 1.48 & 0.50 \\
\hline 4 & $\begin{array}{l}\text { Helped the adolescent when } \mathrm{s} / \mathrm{he} \text { found something difficult to do in a } \\
\text { game }\end{array}$ & 56.1 & 43.9 & 1.44 & 0.50 \\
\hline 5 & Helped the child when something has bothered him/her on the internet & 57.4 & 42.6 & 1.43 & 0.50 \\
\hline 6 & $\begin{array}{l}\text { Talked to the adolescent about what to do if something on the game } \\
\text { bothered him/her }\end{array}$ & 58.4 & 41.6 & 1.42 & 0.49 \\
\hline & Average mean & & & 1.46 & \\
\hline \multicolumn{6}{|c|}{ Active mediation of Internet use } \\
\hline 1 & $\begin{array}{l}\text { Encourage your adolescent to explore and learn things from games on } \\
\text { their own }\end{array}$ & 47.0 & 53.0 & 1.53 & 0.50 \\
\hline 2 & Play online games with him/her & 57.4 & 42.6 & 1.43 & 0.50 \\
\hline 3 & Talk to him/her about proper gaming habits & 57.4 & 42.6 & 1.43 & 0.50 \\
\hline 4 & Stay nearby when s/he is playing game & 64.9 & 35.1 & 1.35 & 0.48 \\
\hline \multirow[t]{2}{*}{5} & Sit with him/her while s/he is playing game & 69.3 & 30.7 & 1.31 & 0.46 \\
\hline & Average mean & & & 1.41 & \\
\hline \multicolumn{6}{|c|}{ Technical mediation } \\
\hline 1 & Installed filtering software & 69.6 & 30.4 & 1.30 & 0.46 \\
\hline 2 & Asked for service to limit Internet use & 72.0 & 28.0 & 1.28 & 0.45 \\
\hline \multirow[t]{2}{*}{3} & Kept track of the websites & 74.7 & 25.3 & 1.25 & 0.44 \\
\hline & Average mean & & & 1.28 & \\
\hline \multicolumn{6}{|c|}{ Monitoring mediation } \\
\hline 1 & Check their profile on a gaming platform & 61.5 & 38.5 & 1.39 & 0.49 \\
\hline 2 & Check which friends or contacts they add to their gaming community & 67.9 & 32.1 & 1.32 & 0.47 \\
\hline 3 & Check game website they visit & 77.4 & 22.6 & 1.23 & 0.42 \\
\hline \multirow[t]{2}{*}{4} & Check email or instant messages & 83.4 & 16.6 & 1.17 & 0.37 \\
\hline & Average mean & & & 1.27 & \\
\hline \multicolumn{6}{|c|}{ Restrictive mediation } \\
\hline 1 & Restrict to give out personal information & 60.1 & 39.9 & 1.40 & 0.49 \\
\hline 2 & Restrict uploading of photos, video or music & 76.0 & 24.0 & 1.24 & 0.43 \\
\hline 3 & Restrict to their own gaming community & 80.7 & 19.3 & 1.19 & 0.39 \\
\hline \multirow[t]{2}{*}{4} & Restrict watching movie & 85.5 & 14.5 & 1.15 & 0.35 \\
\hline & Average mean & & & 1.24 & \\
\hline
\end{tabular}

Categorised based on mean: Low (mean between 1 and 2.5); High (mean between 2.51 and 5)

$M$ Mean, $S D$ Standard deviation

for all constructs were strong as they were higher than 0.7 . Construct reliability was 0.77 for technical mediation, 0.92 for active mediation of internet safety, 0.98 for monitoring 
Table 3 Factor loading of parental mediation items

Parental mediation

\begin{tabular}{|c|c|c|c|c|c|}
\hline & Factor & & & & \\
\hline & 1 & 2 & 3 & 4 & 5 \\
\hline Suggested ways to do online game safely & 0.918 & & & & \\
\hline $\begin{array}{l}\text { Suggested ways to mind your words/actions } \\
\text { while gaming }\end{array}$ & 0.876 & & & & \\
\hline Explained why some games are good or bad & 0.874 & & & & \\
\hline $\begin{array}{l}\text { Helped the adolescent when something in a } \\
\text { game has bothered him/her on the internet }\end{array}$ & 0.756 & & & & \\
\hline $\begin{array}{l}\text { Talked to the adolescent about what to do if } \\
\text { something on the game bothered him/her }\end{array}$ & 0.737 & & & & \\
\hline $\begin{array}{l}\text { Helped the adolescent when } \mathrm{s} / \text { he found } \\
\text { something difficult to do in a game }\end{array}$ & 0.717 & & & & \\
\hline $\begin{array}{l}\text { Encourage your adolescent to explore and } \\
\text { learn things from games on their own }\end{array}$ & 0.466 & & & & \\
\hline $\begin{array}{l}\text { Check which friends or contacts they add to } \\
\text { their gaming community }\end{array}$ & & 0.914 & & & \\
\hline Check their profile on a gaming platform & & 0.878 & & & \\
\hline Check games they play & & 0.835 & & & \\
\hline Check email or instant messages & & 0.654 & & & \\
\hline Restrict use of personal information & & 0.522 & & & \\
\hline Restrict uploading of photos, video or music & & 0.461 & & & \\
\hline Sit with him/her while s/he is playing game & & & 0.930 & & \\
\hline Stay nearby when $\mathrm{s} /$ he is playing game & & & 0.810 & & \\
\hline Play online games with him/her & & & 0.467 & & \\
\hline Talk to him/her about proper gaming habits & & & 0.373 & & \\
\hline Restrict to their own gaming community & & & & 0.909 & \\
\hline Restrict playing games & & & & 0.805 & \\
\hline Kept track of the problematic gaming websites & & & & & 0.749 \\
\hline Asked for service to limit Internet use & & & & & 0.719 \\
\hline Install filtering software & & & & & 0.559 \\
\hline Reliability & 0.92 & 0.89 & 0.83 & 0.9 & 0.8 \\
\hline Total & 9.5 & 2.4 & 1.5 & 1.2 & 1.2 \\
\hline$\%$ of Variance & 43.3 & 10.8 & 6.6 & 5.6 & 5.3 \\
\hline Cumulative \% & 43.3 & 54.1 & 60.8 & 66.3 & 71.7 \\
\hline Kaiser-Meyer-Olkin Measure of Sampling Adequacy & 0.91 & & & & \\
\hline \multicolumn{6}{|l|}{ Bartlett's Test of Sphericity } \\
\hline Approx. Chi-Square & & & & & 4363.143 \\
\hline Degree of freedom & & & & & 231 \\
\hline Sig & & & & & 0.000 \\
\hline
\end{tabular}

Extraction Method: Maximum Likelihood

Rotation Method: Promax with Kaiser Normalization. ${ }^{a}$

a. Rotation converged in 6 iterations 
Table 4 Convergent validity assessment of measurement model for parental mediation

\begin{tabular}{llllllll}
\hline & 1 & 2 & 3 & 4 & 5 & CR & AVE \\
\hline 1 Technical mediation & 0.74 & & & & & 0.78 & 0.54 \\
2 Safety & 0.54 & 0.80 & & & 0.92 & 0.64 \\
3 Monitoring & 0.70 & 0.50 & 0.76 & & & 0.89 & 0.57 \\
4 Use & 0.57 & 0.68 & 0.60 & 0.76 & & 0.84 & 0.57 \\
5 Restrictive & 0.45 & 0.48 & 0.47 & 0.51 & 0.88 & 0.87 & 0.78 \\
6 Game addiction & -0.12 & 0.01 & 0.06 & 0.02 & 0.14 & 0.97 & 0.65 \\
\hline
\end{tabular}

$C R$ Construct reliability, AVE Average Variance Extracted

0.84 for active mediation of internet use, 0.87 for restrictive mediation, and 0.97 for problematic game use.

\section{Confirmatory Factor Analysis}

To assess the construct validity of measurement model of parental mediation, which is obtained using EFA, a confirmatory factor analyses (CFA) was performed using AMOS software 22 based on the variance-covariance metrics (using Pattern Matrix Builder plugin available in statwiki ${ }^{1}$ ). Firstly, standardized factor loadings in each construct were assessed and standardized loadings below 0.5 were deleted as suggested by many scholars (e.g., Kline 2011; Hair et al. 2010). Then, modification indices technique was used to modify the model validity in order to achieve greater fit of the model. Finally, the measurement model validity and the model fit were assessed.

\section{Structural Equation Modelling}

To check whether the model proposed for this study fitted with the theoretical model of the parental mediation effect on youth's problematic online gaming, Structural Equation Modelling with AMOS was used. The overall fit and acceptability of the online risk constructs, and the overall goodness of fit for the study model were evaluated using standardized maximum likelihood estimations since this is the most widely used fitting function for structural equation models (Schermelleh-Engel et al. 2003). Model-fit improvement, based on this MI technique, is measured by a reduction in Chi-square; so, the researchers were looking for a non-significant $(p>0.05)$. SEM using AMOS provides the overall chi-square $(\chi 2)$ value with its degrees of freedom and probability value. These are to assess a quick overview of model fit (Byrne 2010). The chi-square value is the traditional measure for assessing overall model fit and comparing model with data proposed. A good model fit would provide an insignificant result at a 0.05 threshold. However, for large sample size mostly is not significant (Hooper et al. 2008). Due to the limitation and sensitively of chi-square, researchers report alternative indices to assess model fit such as relative/normed chi-square $(\chi 2 / \mathrm{df})$. Recommendations range from 2 to 5 (Hooper et al. 2008). The chi-square value on this study was 1333.760 , degrees of freedom was 609 , and probability level was 0.000 . The relative/normed chi-square was $1333.760 / 609=$ 2.19 and this indicates a model fit. The Mean Square Error of Approximation (RMSEA) was

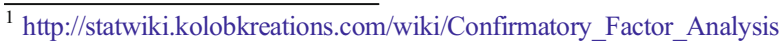


0.064, Goodness of Fit Index (GFI) was 0.81, Adjusted Goodness of Fit Index (AGFI) was 0.69, the Tucker-Lewis Index (TLI) was 0.9, and the Comparative Fit Index (CFI) was 0.91. All meet the criteria of model fit scince a cut-off of 0.90 is generally accepted as indicating a good fit (Hair et al. 2010). Also, the RMSEA as one of the popular fit indices, was assessed which suggested to be $<0.05$ or $<0.08$ (RMSEA=0.06) (Fig. 1).

Exploratory Factor Analysis was run to examine how many factors explained PMM. The five-factor scale extracted by EFA, was tested through Confirmatory Factor Analysis to determine if the number of factors conform to what is expected on the basis of the study. All items loaded on the expected number of factors. The result shows that the five-factor PMM developed by the European Kids Online project (Livingstone et al. 2011) is not applicable for the Malaysian context. However a re-constructed model of parental mediation was reliable and valid. Two items of 'restrictive mediation' were extracted into 'monitoring mediation' (i.e., restricting the uploading of photos, video or music; restricting the giving out of personal information). One item of the 'active mediation of Internet use' was extracted into 'active

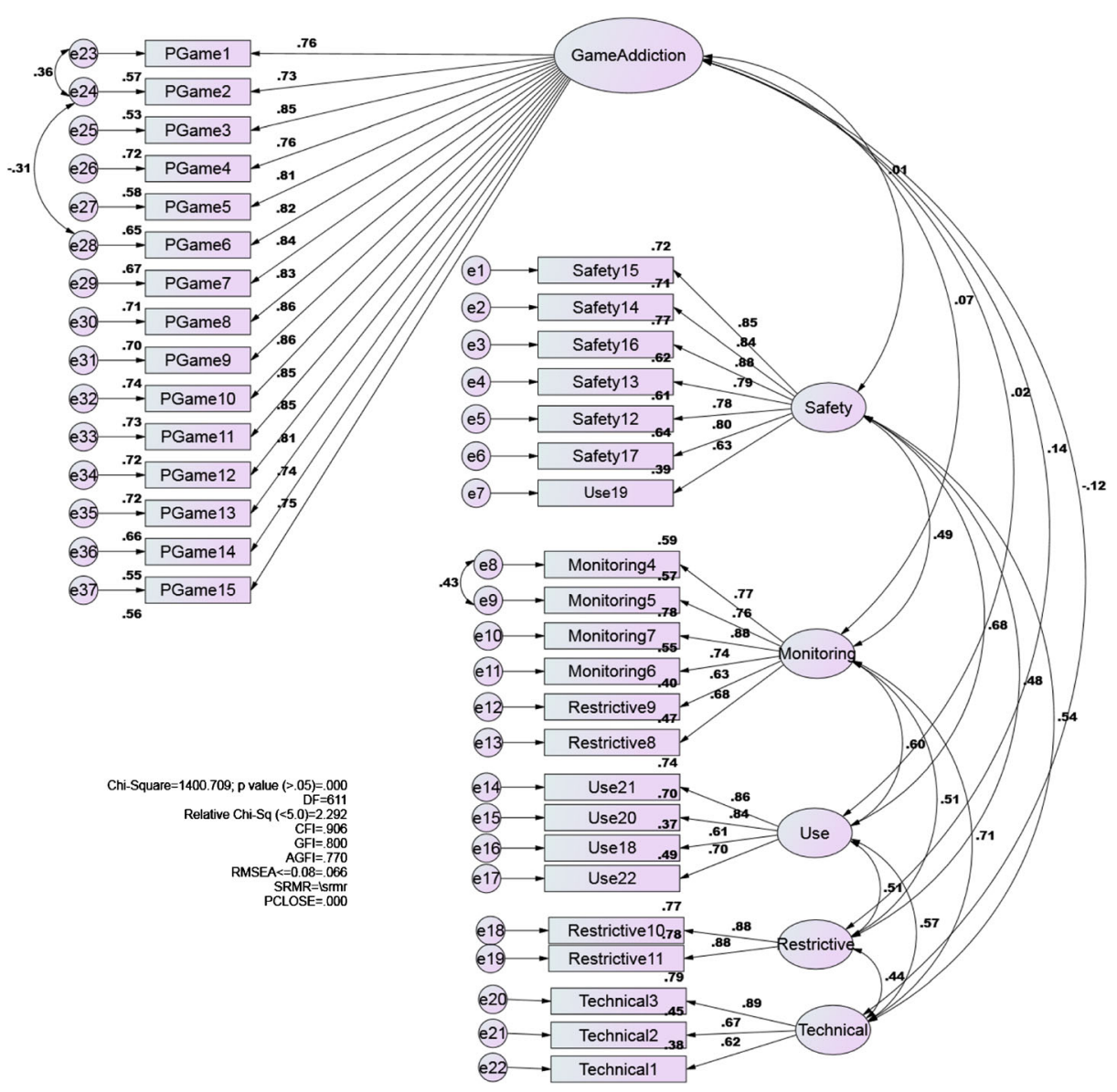

Fig. 1 Measurement model test 
Table 5 Regression Weights of parental mediation effects on problematic of game

\begin{tabular}{lllllll}
\hline & & & Estimate & S.E. & C.R. & P \\
\hline Game Addiction & $<-$ & Monitoring & 0.267 & 0.109 & 2.443 & 0.015 \\
Game Addiction & $<-$ & Technical & -0.349 & 0.105 & -3.331 & $* * *$ \\
Game Addiction & $<-$ & Restrictive & 0.224 & 0.095 & 2.373 & 0.018 \\
Game Addiction & $<-$ & Use & -0.014 & 0.107 & -0.132 & 0.895 \\
Game Addiction & $<-$ & Safety & -0.006 & 0.078 & -0.070 & 0.944
\end{tabular}

Estimate: Unstandardized regression weights; S.E. Standardized regression weights

mediation of Internet safety' and was the item 'encourage your adolescent to explore and learn things from games on their own'. The rest of the items remained within their own factors.

The result of EFA for the Problematic Online Gaming Questionnaire (POGQ) shows the items used in this study was only explained in one factor and is not the same as the initial work carried out on the instrument. In this study, 15 items were found to be reliable and valid. However, all of the items were explained in only one factor.

The study used SEM to test the model of parental mediation effect on Problematic Online Gaming (Table 5; Fig. 2). The result shows from five factors of parental mediation, only technical mediation had negative effect on problematic online gaming $(B=-0.35$; p: 0.00$)$. Restrictive $(B=0.22 ; \mathrm{p}: 0.018)$ and monitoring mediation $(B=-0.27 ; \mathrm{p}: 0.15)$ had positive

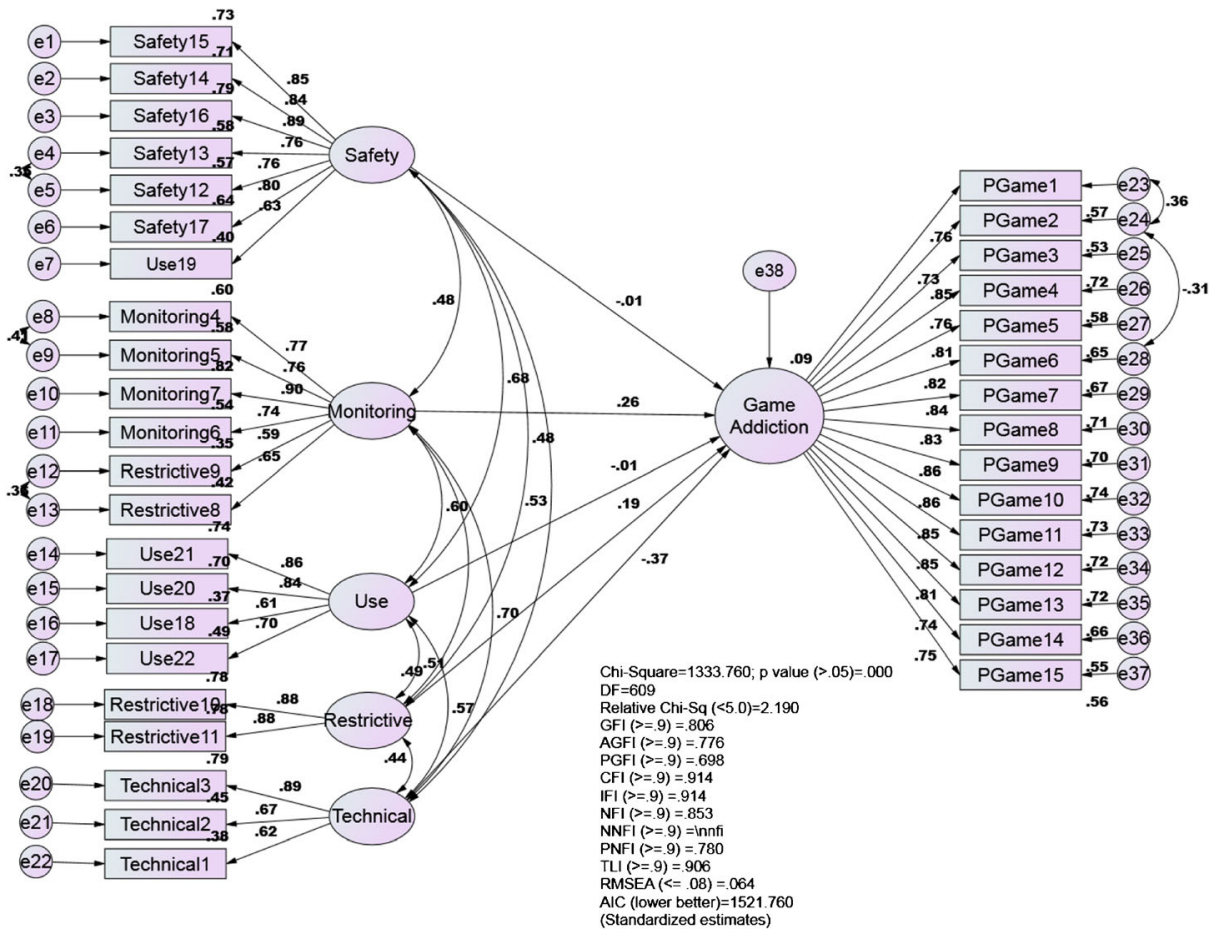

Fig. 2 Structural Equation modelling of parental mediation model and Problematic Online Gaming Questionnaire 
effects on problematic online gaming. More specifically, the more restrictive and monitoring mediation there is, the more problematic online gaming there would be, and the more technical mediation the less problematic online gaming. Active mediation of Internet use and Active mediation of Internet safety have no effect on Problematic Online Gaming.

\section{Discussion}

Based on the findings of the present study we can primarily attest that the five-factor PMM of children internet safety, adapted from EU Kids Online project (namely technical mediation, monitoring mediation, restrictive mediation, active mediation of internet safety, and active mediation of internet use) need further modifications to be applicable in the context of Malaysia. This conclusion is in the line with the findings of Teimori et al. (2014), from a survey on Malaysian children aged 9-16 years. Furthermore, the present results demonstrate that Malaysian parents are more likely to apply active mediation of Internet safety compared to other strategies, whereas restrictive mediation is the least likely to be used. This result was also in line with the study by Teimori et al. (2014). Thirdly, among five parental mediation strategies, only technical mediation which is refers to utilizing software/service to limit adolescents' online gaming is a predictor to decrease the likelihood of exposure to Problematic Online Gaming, while Parental monitoring and restrictive mediation increased Problematic Online Gaming and active mediation of internet safety/use was not a predictor of Problematic Online Gaming.

Moreover, the results of this study have shed light on another prevalent yet erroneous approach towards the role of parental mediation models in decreasing the negative impacts of media on adolescents (Fisher et al. 2009; Lee 2012; Wisniewski et al. 2014). The findings of the present study demonstrate that adolescents' knowledge and experiences about new media often surpass that of their parents, and consequently the traditional parental mediation methods only stand a small chance against the potentially negative effects of new media.

This study has come up with this understanding that quite possibly adolescents and young adults who playing online games more frequently, put themselves at the risk online game addiction and exposure to violent and/or sexual content. At the same time, the extended influence of internet and online games on children and young adults makes the severity of the problem even higher by the fact that the initial stages of such events might simply happen right under the watchful eyes of their caring parents at the very restricted time that is given to the them to have some fun on web. Such issues necessitate extra involvement of not only parents but school teachers with such studies to improve their knowledge about new media and the ways that is can affect the children under their care.

However, all the negative aspects of the online gaming should not makes us ignore the opportunities that are associated with such activities. With regard to this subject matter, there have also been reports of rather contradictory findings on the effects of playing computer games and online gaming, as Latif and Sheard (2009) raised some critically positive reinforcements for such activities, indicating that the versatility of online games in terms of platforms and challenges that the gamers have to go through may eventually improve their social and analytical skills. Nonetheless, such studies have also specified that it is not purely the games that improve the applicants social or analytical skills but the method that they are approached and diffused would play the most important role in that respect. At the same time it is noteworthy that not all online games have such positive effects on adolescents. Therefore, 
the active cooperation of parents and teachers in selection and proper incorporation of such games is required.

Due to the growing number of indicated problems concerning online gaming, it has become an absolute necessity to develop a model to reduce game-related problems. The Problematic Online Gaming Questionnaire (POGQ) applied in this study fulfilled the reliability and validity requirements applied on such instruments. However, in this study, the POGQ was not multifactorial like the initial study. The one-factor measurement is applicable for all types of online games and it covered all problems experienced by the players.

As this paper has discussed, in the case of youth in Malaysia, parents' monitoring strategies were not the most effective ways to reduce negative effects of the online gaming. However, as long as parents' mediation role is limited to the technical methods, they need to improve and update their knowledge in using this strategy. At the same time, since restrictive and monitoring strategies were found to increase the likelihood of involvement in problematic online gaming, it is suggested that parent who are using these methods need to be reconsider their mediation strategies.

The outcomes of the current study have illustrated the superiority of technical mediations over co-viewing and active mediation. However, there are a number of issues should be taken into consideration before approving technical mediation as the most efficient parental mediation. The finding of previous research have made it evident that too much of restriction or low levels of restriction generates consequences such as less interest towards parents, greater tendency towards the banned content and even hostility (Nathanson 1999; Peterson and Hann 1999; see also Hoffman 1970). At the same time, an uneducated restriction of media application not only lowers the chances of exposure to both risks and opportunities but also underestimates media's freedom of expression and adolescents' right for freedom of access to media.

Such issues necessitate further research on additional mediation strategies such as participatory learning. In participatory learning, parents and children are supposed to improve and recalibrate their information about interaction with (and through) digital media. In conclusion, further research on participatory learning among parents and adolescents may prove to be a sixth parental mediation strategy after technical mediation, monitoring mediation, restrictive mediation, active mediation of internet safety, and active mediation of internet use. At the same time, there is a need for further research on how to involve teachers with such mediation strategies as they may provide a different level of observation and mediation with adolescents' online activities and their subsequent social interaction.

\section{References}

Atkin, D. J., Greenberg, B. S., \& Baldwin, T. F. (1991). The home ecology of children's televison viewing: parental mediation and the new video environment. Journal of Communication, 41(3), 40-52.

Azim DHBF, Zam NABM, Rahman WRA. (2011). Internet addiction between malaysian male and female undergraduate human sciences students of the International Islamic University Malaysia. The 6th International Postgraduate Research Colloquium, Malaysia, 58-74. doi:10.1111/1467-8624.00424.

Bartlett, M. S. (1954). A note on the multiplying factors for various chi square approximations. Journal of Royal Statistical Society, 16(Series B), 296-298.

Buijzen, M., \& Valkenburg, P. M. (2005). Parental mediation of undesired advertising effects. Journal of Broadcasting \& Electronic Media, 49(2), 153-165. 
Buijzen, M., Rozendaal, E., Moorman, M., \& Tanis, M. (2008). Parent versus child reports of parental advertising mediation: exploring the meaning of agreement. Journal of Broadcasting \& Electronic Media, 52(4), 509525 .

Bybee, C. R., Robinson, D., \& Turow, J. (1982). Determinants of parental guidance of children's television viewing for a special subgroup: mass media scholars. Journal of Broadcasting, 26(3), 697-710.

Byrne, B. M. (2010). Structural equation modeling with AMOS (Second.). New York: Routledge.

Cattell, R. B. (1966). The scree test for the number of factors. Multivariate Behavioral Research, 1, $245-276$.

Chen, C. (2010). Information visualization. Wiley Interdisciplinary Reviews: Computational Statistics, 2(4), $387-403$.

Clark, L. S. (2011). Parental mediation theory for the digital age. Communication Theory, 21(4), 323-343.

Daud, A., Omar, S. Z., Hassan, M. S., Bolong, J., \& Teimouri, M. (2014). Parental Mediation of children's positive use of the Internet Azlina. Life Science Journal, 11(8), 360-369.

Demetrovics, Z., Urbán, R., Nagygyörgy, K., Farkas, J., Griffiths, M. D., Pápay, O., \& Oláh, A. (2012). The development of the problematic online gaming questionnaire (POGQ). PloS ONE, 7(5), e36417. doi:10. 1371/journal.pone.0036417.

Dishion, T. J., \& McMahon, R. J. (1998). Parental monitoring and the prevention of child and adolescent problem behavior: a conceptual and empirical formulation. Clinical Child and Family Psychology Review, 1(1), 6175. Retrieved from http://www.ncbi.nlm.nih.gov/pubmed/11324078.

Duerager, A., \& Livingstone, S. (2012). How can parents support children's Internet safety? London: EU Kids Online Network.

Fisher, D. A., Hill, D. L., Grube, J. W., Bersamin, M. M., Walker, S., \& Gruber, E. L. (2009). Televised sexual content and parental mediation: influences on adolescent sexuality. Media Psychology, 12(2), 121-147. doi:10.1080/15213260902849901.

Fornell, C., \& Larcker, D. F. (1981). Evaluating structural equation models with unobservable variables and measurement error. Journal of Marketing Research, 18(1), 39-50.

Fujioka, Y., \& Weintraub, A. E. (2003). The implications of vantage point in parental mediation of television and child's attitudes toward drinking alcohol. Journal of Broadcasting \& Electronic Media, 47(3), 418-434.

Gaskin, J. (2012), "Name of tab", Stats Tools Package. http://statwiki.kolobkreations.com. Accessed 25 Sept 2014.

Griffiths, M. D., Kuss, D.J., \& Ortiz de Gortari, A. (2013). Videogames as therapy: a review of the medical and psychological literature. In I. M. Miranda \& M. M. Cruz-Cunha (Eds.), Handbook of research on ICTs for healthcare and social services: developments and applications (pp.43-68). Pennsylvania: IGI Global.

Griffiths, M. D., Kuss, D. J. \& Demetrovics, Z. (2014). Social networking addiction: an overview of preliminary findings. In K. Rosenberg \& L. Feder (Eds.), Behavioral addictions: criteria, evidence and treatment (pp.119-141). New York: Elsevier.

Hair, J. F., Black, W. C., Babin, B. J., \& Anderson, R. E. (2010). Multivariate data analysis (7th ed.). New Jersy: Pearson Prentice Hall.

Hoffman, M. L. (1970). 'Moral development'. In: P. H. Mussen (ed.), Carmichael's Manual of Child Psychology, Volume 2. New York: Wiley, pp. 261-360.

Hooper, D., Coughlan, J., \& Mullen, M. R. (2008). Structural equation modelling: guidelines for determining model fit. Electronic Journal of Business Research Methods, 6(1), 53-60.

Ismail, K. (2011, October 11). Cyber-duped parents. Malay Mail. Kuala Lampour. Retrieved from http://www. cybersecurity.my/en/knowledge_bank/news/2011/main/detail/2089/index.html.

Kaiser, H. F. (1974). An index of factorial simplicity. Psychometrika, 39(1), 31-36.

Kapahi, A., Ling, C. S., Ramadass, S., \& Abdullah, N. (2013). Internet addiction in Malaysia causes and effects. iBusiness, 05(02), 72-76. doi:10.4236/ib.2013.52009.

Kirkpatrick, L. A., \& Shaver, P. R. (1990). Attachment theory and religion: childhood attachments, religious beliefs, and conversion. Journal for the Scientific Study of Religion, 29(3), 315-334.

Kline, R. B. (2011). Principles and practice of structural equation modeling (3rd ed.). New York: Guilford Press.

Latif, R. A., \& Sheard, J. (2009). Social skills among students while playing computer games in class: a case study in Malaysia. Paper presented at the future computer and communication, 2009. ICFCC 2009. International Conference on, 3-5 April 2009.

Lee, S.-J. (2012). Parental restrictive mediation of children's internet use: effective for what and for whom? New Media \& Society, 15(4), 466-481. doi:10.1177/1461444812452412.

Lee, S.-J., \& Chae, Y.-G. (2007). Children's internet use in a family context: influence on family relationships and parental mediation. Cyber Psychology \& Behavior, 10(5), 640-644.

Liau, A. K., Khoo, A., \& Ang, P. H. (2008). Parental awareness and monitoring of adolescent Internet use. Current Psychology, 27(4), 217-233. doi:10.1007/s12144-008-9038-6.

Livingstone, S., \& Helsper, E. J. (2008). Parental mediation of children's internet use. Journal of Broadcasting \& Electronic Media, 52(4), 581-599. 
Livingstone, S., Haddon, L., Görzig, A., \& Olafsson, K. (2011). Risks and safety on the Internet: The perspective of European children Kids Online network. LSD, London. Retrieved from https://www.google.com/url?sa= $\mathrm{t} \& \mathrm{rct}=\mathrm{j} \& \mathrm{q}=\& \mathrm{esrc}=\mathrm{s} \&$ source $=$ web $\& \mathrm{~cd}=1 \& \mathrm{ved}=0 \mathrm{CB} 8 \mathrm{QFjAA} \& u r \mathrm{l}=\mathrm{http} \% 3 \mathrm{~A} \% 2 \mathrm{~F} \% 2 \mathrm{Fwww} \cdot \mathrm{lse} \cdot \mathrm{ac} . \mathrm{uk} \%$ 2Fmedia\%401se\%2Fresearch\%2FEUKidsOnline\%2FEU\%2520Kids\%2520II\%2520(2009-11)\% 2FSurvey\%2FTechnical\%2520report.PDF\&ei=A_0lVMbpEdSgugTMkIG4BA\&usg=AFQjCNHq-Mo-F_ 6u9jVgwTyQbAMVD2C2IQ\&sig2=Dlc3369cJf0K̈lmftXHfxVg.

Lwin, M. O., Stanaland, A. J. S., \& Miyazaki, A. D. (2008). Protecting children's privacy online: how parental mediation strategies affect website safeguard effectiveness. Journal of Retailing, 84(2), 205-217.

Mesch, G. (2009). Social bonds and Internet pornographic exposure among adolescents. Journal of Adolescence, 32(3), 601-618. doi:10.1016/j.adolescence.2008.06.004.

Nathanson, A. I. (1999). Identifying and explaining the relationship between parental mediation and children's aggression. Communication Research, 26(2), 124-143. doi:10.1177/009365099026002002.

Nathanson, A. I. (2002). The unintended effects of parental mediation of television on adolescents, Media Psychology, 4, 207-230.

Nathanson, A. (2010). Using television mediation to stimulate nontraditional gender roles among Caucasian and African American children in the US. Journal of Children and Media, 4(2), 174-190. doi:10.1080/ 17482791003629644.

Nikken, P., \& Jansz, J. (2006). Parental mediation of children's videogame playing: a comparison of the reports by parents and children. Learning, Media and Technology, 31(2), 181-202. doi:10.1080/ 17439880600756803.

Nikken, P., \& Jansz, J. (2011). Parental mediation of young children's internet use, 1-26.

Pápay, O., Nagygyörgy, K., Griffiths, M.D. \& Demetrovics, Z. (2014). Problematic online gaming. In K. Rosenberg \& L. Feder (Eds.), Behavioral addictions: criteria, evidence and treatment (pp.61-95). New York: Elsevier.

Peterson, G. W., \& Hann, D. (1999). Socializing parents and children in families. In M. B. Sussman, S. K. Steinmetz, \& G. W. Peterson (Eds.). Handbook of marriage and the family (pp. 327-370). New York: Plenum Press.

Schermelleh-Engel, K., Moosbrugger, H., \& Müller, H. (2003). Evaluating the fit of structural equation models: tests of significance and descriptive goodness-of-fit measures, $8(2), 23-74$.

Shek, D. T. L. (2005). Perceived parental control and parent-child relational qualities in Chinese adolescents in Hong Kong. Sex Roles, 53(9-10), 635-646. doi:10.1007/s11199-005-7730-7.

Shin, W., \& Huh, J. (2011). Parental mediation of teenagers' video game playing: antecedents and consequences. New Media \& Society, 13(6), 945-962.

Shin, W., Huh, J., \& Faber, R. (2012). Tweens' Online Privacy Risks and the Role of Parental Mediation. Journal of Broadcasting \& Electronic Media, 56(4), 37-41. Retrieved from http://www.tandfonline.com/doi/abs/10. 1080/08838151.2012.732135.

Smetana, J. G., \& Daddis, C. (2002). Domain-specific antecedents of parental psychological control and monitoring: the role of parenting beliefs and practices. Child Development, 73(2), 563-580. doi:10.1111/ 1467-8624.00424.

Soh, P. C.-H., Yan, Y. L., Ong, T. S., \& Teh, B. H. (2012). Digital divide amongst urban youths in Malaysia myth or reality? Asian Social Science, 8(15). doi:10.5539/ass.v8n15p75.

Stattin, H., \& Kerr, M. (2000). Parental monitoring: a reinterpretation. Child Development, 71(4), 1072-1085.

Teimori, M., Hassan, M. S., Bolong, J., Tamam, E., Adzaruddin, N. A., \& Daud, A. (2014). Reexamining parental mediation model for children internet safety. Journal of Language and Communication, 1(2), 209-220.

Valkenburg, P. M., Krcmar, M., Peeters, A. L., \& Marseille, N. M. (1999). Developing a scale to assess three styles of television mediation: "instructive mediation", "restrictive mediation", and "social coviewing". Journal of Broadcasting \& Electronic Media, 43(1), 52-66. doi:10.1080/08838159909364474.

Wisniewski, P., Xu, H., Rosson, M. B., \& Carroll, J. M. (2014). Adolescent online safety: the "moral" of the story, (Cmd), 1258-1271.

Zin, N. A. M., Yue, W. S., \& Jaafar, A. (2009). Digital game-based learning (DGBL) model and development methodology for teaching history. WSEAS Transactions on Computers, 8(2), 322-333. 